\title{
Journal of the Society of Brewing, Japan
}

\author{
Vol.52. Nos. $7-12(1957)$
}

\section{Relations between the properties of Aspergilli and the qualities of sake.}

On the brewing of saké with different kinds of Aspergilli (5)

\author{
Studies on Koji (XV) \\ (No. 7.551 556)
}

by

Hideya Murakami, Mitori Kawai, Shin Ueno, Masao Murayama, Kiyoshi YosHIZAwA and Akira Mryahara (Brewing Experimental Station, Tax Administration Agency. 2-6, Takinogawa. Kita-ku, Tokyo)

(Received June 10; 1957)

The "Chuginjo-brewing" — brewing with highly polished rice under lower temperature was carried out to research the influence of the properties of Aspergilli on the qualities of saké. The Aspergilli were used two kinds, the one is No. 23 and the other No. 40 both included in the Aspergillus oryzae group. No. 23 is suitable for the ordinary brewing but unsuitable for the "Chuginjo-brewing" and No. 40 is on the contrary. In other words, the properties of fungi are changeable alternately by the brewing conditions. The broning of koji and saké cake was generated only when No. 40 was used as reported formerly. Various reverse phenomena observed in these brewing tests were discussed from various points of views, especially from the point of change of oxygen requirement by the cultural conditions.

\section{Trace elements of “ miyamizu” \\ by $\quad$ (No.7 $562 \sim 565)$}

\section{Atsushi Matsubara and Tomosaburo Hirotsu}

(Received May 20, 1957)

Spectrographs of the evaporation residues such mineral springs around Kabutoyama as Arima, Takarazuka, Hirano, Sakasegawa etc. resembled so closely with each other, as if they were obtained from one and the same substance. This fact may be explained from their origin; they are considered to be originated from the same magma reservior of Kabutoyama-volcano.

The brewing water of Nishinomiya, so called miyamizu, gives also a similar spectrograph as the above mineral waters. This striking fact suggests that the miyamizu is essentially a mineral water of Kabutoyama type, running into the miyamizu-bearing sand layer at some place or places in the north outskirt to form the ground flow.

Besides such common elements as $\mathrm{Ca}, \mathrm{Na}, \mathrm{Mg}, \mathrm{K}, \mathrm{Si}, \mathrm{Fe}$ and $\mathrm{Al}$, the spectrographs show the lines of $\mathrm{B}$ most predominantly. Next to $\mathrm{B}$ in intensity, $\mathrm{Sr}, \mathrm{Ba}, \mathrm{Ni}, \mathrm{Mn}, \mathrm{Ag}, \mathrm{Cu}, \mathrm{C}$, and $\mathrm{Li}$ give distinct lines. Those of $\mathrm{Ti}, \mathrm{Cr}$ and $\mathrm{Pb}$ are weaker.

The above generalization holds true for the mineral waters and miyamizu except that the lines of $\mathrm{Ba}$ are weaker in miyamizu. $\mathrm{Co}$, Mo and $\mathrm{V}$ are found in miyamizu, but not in mineral waters. 


\title{
Chromatographic separation and determination of free Amino acid of wine.
}

(No. $7 \quad 569 \sim 571$ )

by

\author{
Sadao Iwano(Institute of Applied Microbiology. University of Tokyo)
}

(Received June 15, 1957)

Amino acids in wine samples were analyzed by the method proposed by Awapaa-Landua. Wine samples were fractionated by adsorption and elution through an ion-exchange colume. After concentration ámino acids were separated by paper chromatography. Barbera wine (fabricated in Italy), 1955 vintage, contained alanine 4.45, glutamic acid 4.29, cystine 3.96, lysine 6. 38, threonine 4.67, proline $20.68 \mathrm{mg} /$ liter. Traces Traces of glycine, serine, histidine, arginine, leucine and $\gamma$-aminobuthyric acid were also detected.

\section{Studies on the influence of inrganic salts in saké brewing.}

(Part 1) The influence on Saké yeasts by the addition of Aluminum salts.

by

(No.7 571 577)

Kyogoro Ito and Jun SAto (Research Inst. Indust. Pref. Iwate, Morioka city)

(Received June 15, 1957)

1) We investigated the influence on the actions of multiplication, fermentation, respiration of Saké yeasts in the medium added with chloride or pulphate of aluminum, or potassium alum.

2) It was recognized that multiplication of Saké yeasts was markedly inhibited by adding Alslats. Its principal inhibition was chiefly shown to be due to the decrease of phosphate as the essential nutrient rather than to the physiological failure of yeasts.

The degree of inhibition was not remarkable within $0.07 \%$ of Al-salt. The activity of multiplication in concentration of $0.1 \%$ was from a quarter to a half compared with the blank test and it was inhibited perfectly in $0.5 \%$.

3) The inhibition of fermentation was also recognized, but it was not more remarkable than that of multiplication. The extreme influence was not shown even when the addition of salts was over $0.05 \%$.

4) For the respiratory action the effect of the Al-salts was negligible.

5) We think that there are no great obstacles in the application of Al-salts in Saké manufacturing when suitable amounts are used.

The change of yeast number in prepared moto-mash (yeast culture)

and moromi-mash (main beer) in saké-brewing.

$$
\text { by }
$$

(No.7 $577 \sim 582)$

\section{Masakazu Yamada and Zenichi Nakamura (Brewing Experimental Station, Tax Administration Agency)}

(Received June 15,1957)

In moto mash (yeast culture) after it was completely prepared, the yeast number ordinarily 
decreases day by day from 400 millions per c.c. and the staining ratio of yeasts with mlthyleneblue increases suddenly.

It may perhaps be due to the conducts of remakably accumulated acids $(1.1 \%$ as lactic acid) and alcohol (11-14\%) in moto mash.

Yeast number in moromi mash (main beer) often reaches 500 millions in the high-foam stage (av. 10 days after pitching) and the number does not decrease till the end of the main fermentation.

\section{On the state of surface in moroma-mash (main beer) at the end of the fermentation in sake-brewing.}

by

(No. 7 582 586)

Masakazu YAMAdA (Brewing Experimental Station, Tax Administration Agency (Received June 15,1957)

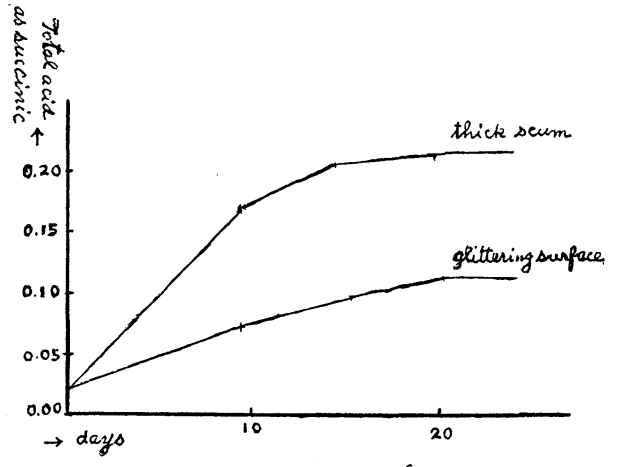

Moromi-mash of sake shows ordinarily either of two states of surface at the end of its main fermentation: One state is that of the flat, glittering surface and the other that of the thick scum consisting of foam of carbon-dioxide gas, dextrin paste, yeast cells and oil of fatty acid ethyl esters.

In the former case, the fermentation seems to be carried out purely with yeasts and the period of moromi-mash is short-15-20 days. Consequently the sake has little acid and shows light taste.

On the other hand in the lather case, the fermentation is generally extremely retarded at the end and so the period of moromi-mash becomes very long-30-40 days. In this case the sake has much acid and shows heavy taste.

As this increase of acid is already seen in the high-foam stage at av. 10 days after pitching.

It is considered that the thick scum is due to infection of some bacteria and that the retardation of alcoholic fermentation may perhaps be due to accumulation of non-fermentable sugars by the bacteria. The responsible bacteria may come from atmosphere or koji.

Acid formation is shown by the following diagram:-

\section{Studies on "protein-turbidity" in sake (Supplement to Part2)}

On the comparison of flocculating activity of various enzyme preparations

$$
\text { by }
$$

(No. 8 639 642)

\section{Hiroichi Akiyama and Masayuki Harada (Brewing Experimental Station, Tax Administration Agency)}

(Received July 10.1957)

In the previous paper, it was shown that the flocculating enzyme of saké-protein-turbidity belonged to proteolytic enzymes. For the elucidation of this enzyme, various kinds of enzyme pr- 
eparations and saké samples were examined.

1. There was not always proportional relation between proteolytic activity and flocculating activity. Such enzyme preparations had the highest flocculating activity on saké turbidity that had maximum activity of proteolysis at $\mathrm{pH} 7$.

2. All of pasteurized and preserved saké samples contained the matter which was flocculated and precipitated by these enzyme preparations. Some of saké samples were easily flocculated, while others were not. These characters would be influenced by physical and chemical properties of saké.

\title{
Effect of mixture of the different kinds of Aspergilli on the browning of kōji
}

by

(No. 8 643 645)

\author{
Hideya Murakami and Hiromichi Yano (Brewing Experimental Station, \\ Tax Administration Agency)
}

(Received July 20.1957)

There are two kinds of Aspergilli (Koji molds): one causes rapidly the browning of koji and the other brings about the browning slowly or does not. The blackening of kojji was compared by mixtures of these two kinds of aspergilli at various amounts of their conidia.

Thus, it was confirmed that the browning of kōji depended on the amount of conidia havingthe rapid blackening properties, that is, we could control at will the color change of kōji by mixing rightly these conidia.

\section{On various conditions of browning}

Enzymological studies on the browning of koji (part II)

by (No. 8 645 651)

Hideya Murakami, Shin Ueno, Mitori Kawai, Toshio Takegoshi and

Takenori Or (Brewing Experimental Station, Tax Administration Agency)

(Received July 15.1957)

The color of kōji left alone for a few hours or days under the natural conditions (at a lower temperature in the presence of air) changed gradually from its original white color to brown or reddish brown; thus the color of various goods manufactured with koji, for instances, saké, amasaké, mirin, miso and shōyu were influenced.

It was proved by the experimental koji making or the practical brewing trials that the browning of kōji or its preparations was attributed by the properties of the Aspergilli used in the koji making.

In this report the conditions of browning of kōji extract were discussed and summarized as follows.

1) The color intensity of kōji extract increased in proportion to the period of cultivation, but the progressing degree of browning was highest after about $50 \sim 60$ hours of cultivation.

2) Both the color intensity and the progressing degree of browning were highest in the cultivation at $32 \sim 36^{\circ} \mathrm{C}$, but they were not much lowered at $41^{\circ} \mathrm{C}$. 
3) The color intensity was highest with the Aspergilli cultivated on the wheat bran at $120 \%$ moisture, while the progressing degree of browning was highest with those at $60 \%$ moisture.

4) The progressing degree of browning of koji extract was highest when extracted with water for 3 hours at $\mathrm{pH} 5 \sim 6$.

5) The progressing degree of browning of kōji extract was highest for $3 \sim 4$ hours after extraction, especially under the conditions of $10 \sim 40^{\circ} \mathrm{C}$ and $\mathrm{pH} 5 \sim 6$.

\title{
Studies on the colour of Soy-sauce. Part2.
}

by

\author{
Masanao Mitur and Eiji Kusaka
} sauce Co.Ltd., Karatu)
(No. 10 816 822)

(Laboratory of Miyajima Soy-

(Received July 29,1957)

Soy-sauce pigment was studied by paper-chromatography and spectrophotometric method.

1) There are two components consisting the Soy-sauce pigment, namely, Kurono's Soyamelanic acid and pigment $\mathrm{F}_{2}$, which is not precipitated with basic lead acetate. The latter is not soluble in common organic solvents, but is soluble in ethanol below $87 \%$. When the tint components of the two represented by Onuki's method are compared the latter is more yellowish and less reddish than the former.

2) Some melanoidins synthesized by various methods and caramel prepared by heating in an atmosphere of $\mathrm{N}_{2}$-gas are studied by paper- chromatography.

3) These 11 pigments - normal brewed Soy-sauce, Kurono's Soyamelanic acid, pigment $\mathrm{F}_{2}$, normal Caramel, $\mathrm{N}_{2}$-gas blowed Caramel, soybean and sweet potato starch hydrolysate, and Melanoidins — are characterized by visible and ultra-violet absorption.

4) The chromatograms of these 11 pigments are photographed, making use of the absorption of ultra-violet ray.

\section{Relation between the browning of kojii and the properties of the Aspergilli}

\author{
Supp1.: Explanation of the exceptional phenomena \\ observed in the brewing of saké \\ Enzymological studies on the browning of kōji (Part.III) \\ (No. 10 830 838) \\ by
}

Hideya Murakami and Mitori KawaI (Brewing Experimental Station,

Tax Administration Agency)

The Aspergilli (Asp. flavus-oryzae group) were classified into three groups, i.e. the aerobic, the anaerobic and the facultative anaerobic, by their amount of oxygen requirement. Their oxidizing enzyme activities and the change of oxygen requirement by the various cultural conditions were comparatively researched.

Of all kinds of properties formerly reported, the oxygene reqirement or the oxidizing enzyme activities of the Aspergilli were most closely connected with the browning of köji. 


\title{
Studies on the influence of inorganic salt on saké brewing.
}

Part 2. The influence of aluminum chloride on the enzymes in Rice Koji.

(No. 11 885 893)

\author{
by
}

\begin{abstract}
Kyogoro ITO and Katsuo OMORI (Reseach Inst. Indust., Iwate Pref.)
\end{abstract}
(Received Oct. 15, 1957)

We studied on the influence of $\mathrm{AlCl}_{3} \cdot 6$ aq upon the main enzymes of Rice Koji, viz., S-amylase, maltase, glucoside bond-hydrolyzing enzyme, protease, oxidative, enzymes and other enzymes, which are thought to be closely connected with Saké brewing.

1) The activities of saccharifying enzymes such as S-amylase, maltase, and glucoside bond hydrolase were scarcely affected by $\mathrm{AlCl}_{3}$. 6 aq.

2) Slight inhibitory effects were recognized to the acid and alkaline protease, when the amount of $\mathrm{AlCl}_{3} \cdot 6$ aq was gradually increased.

3) The $\alpha$-amylase was remarkably inhibited, and the degree of its inhibition was larger in proportion to the concentration of $\mathrm{AlCl}_{3} \cdot 6$ aq. Both lowering of $\mathrm{pH}$ by $\mathrm{AlCl}_{3} \cdot 6$ aq and $\mathrm{Al}$ ions of $\mathrm{AlCl}_{3} \cdot 6$ aq were recognized to be influential especially to the $\alpha$-amylase.

4) The $\alpha$-amylases of commercial 'Diastase' and 'Spitase' in the market were inhibited by $\mathrm{AlCl}_{3} \cdot 6$ aq.

5) The inhibition of $\alpha$-amylase was lessened above a certain concentration of $\mathrm{AlCl}_{3} \cdot 6$ aq (about $0.03-0.05 \%$ of $\mathrm{AlCl}_{3} .6$ aq and below $\mathrm{pH} 4.7$ in reaction substrate.) only when enzyme preparation was crude and acetic acetate buffer was used.

This phenomenone did not occur when $\mathrm{Al}_{2}\left(\mathrm{SO}_{4}\right) \cdot 18$ aq was used. It did not occur even when $\mathrm{AlCl}_{3} \cdot 6 \mathrm{aq}$ was used, in case of purified enzyme solution.

6) This cause was searched for by various methods, but it was not obvious beyond presumption.

7) When the concentration of buffer solution is extremely increased, the inhibition to enzymes by $\mathrm{AlCl}_{3} \cdot 6$ aq is weakened, but the tendency of reaction curve is not transformed.

8) The activities of catalase, peroxidase, tyrosinase and lipase, which are considered to be closely bound with coloring of Rice Koji and Saké, are scarcely affected by $\mathrm{AlCl}_{3} \cdot 6$ aq.

9) There seemed to exist a close relation between the inhibitory action of $\mathrm{AlCl}_{3} \cdot 6$ aq to $\alpha$-amylase in Rice Koji and decreasing of Saké color.

\section{On the determination of DO}

(No. 11 893 896)

\begin{abstract}
Hideya Murakami, Mitori Kawai, Akira Miyahara, Akira Fuse and Hiromichi YANO (Brewing Experimental Station, Tax Administration Agency)
\end{abstract}

(Received Oct. 21, 1957)

For the determination of DO (dissolved oxygen), two methods were compared. The one is Miller's method and the other manometric method by means of the alkaline pyrogallol absorption. We can compare the amount of DO in the various kinds of solutions to a certain degree of accu* 
racy by using parallel these two methods, even if the solutions are chemically complicated, as the koji extract. Because two kinds of values obtained by two methods are awlays parallel but not always proportional.

The heat emission during "koji" incubation

(No. $11901 \sim 904$ )

by

Meiji Suzuki, Yataro Nunokawa and Ichiro Sasaki

(Brewing Experimental Station, Tax Administration Agency)

(Received Oct. 15, 1957)

We measured the energy losses of "koji", which was produced from $25 \%$-polished rice, by a bombe calorimeter in the process of its incubation.

The heat losses were very striking for $30 \sim 45$ hours of incubation, and the total losses of heat during "koji" incubation were $210 \pm 70$ kcals per $1.5 \mathrm{kgrs}$ of raw polished rice.

The amount of $\mathrm{CO}_{2}$ produced was $82 \pm 27 \mathrm{grs} / 1.5 \mathrm{~kg}$ of raw polished rice, when calculated from the energy losses, which were assumed to occur from the decomposition of starch.

Studies on the ripeness of "koji"

(Repot 5) The relation between the proteolytic enzyme activity and incubation temperature of Rice-" Koji"

(No. 11 904 906)

by

Meiji Suzuki, Yataro Nunokawa and Goro Hiroshima (Brewing

Experimental Station, Tax Administration Agency)

(Receive Oct. 15, 1957)

In the previous papers ${ }^{1)}$,2) we reported concerning the above-mentioned problem. One of the $r$ esults was that the rice-"koji" incubated at the temperature higher than $40^{\circ} \mathrm{C}$ had lower proteolytic enzyme power than that incubated lower than $35^{\circ} \mathrm{C}$. As technicians of breweries of "saké ", " miso", and "shoyu" generally have had the opinion about rice-" koji" that the higher the incubation temperature is, the higher is the enzyme activity, our reports seemed to give them a sensation. Our previous studies, however, were made with only a single strain of Aspergillus or$y z a e$, which was isolated from some market seed-“koji". Thus the result we obtained might lack its general applicability. In this reason we have repeated the same examination with many typical strains with different characters. Our results showed that we could ascertain that every rice "koji" made from different strains had the same inclination as we have reported concerning the enzyme activity.

Literature

1) M.Suzuki, Y. Nunokawa etal.: J. Soc. of Brew. Japan 51322 (1956)

2) M. Suzuki, Y. Nunokawa, G. Hiroshima : Ibid. 52 477(1957) 


\title{
Studies on the miso manufacture by using yeasts \\ as the starter.
}

Part 2. The trial manufacture.

(No. 12 975)

by

\section{Hiroshi Hosaka}

(Food Research Institute, Ministry of Agriculture and Frorestry)

(Received Nov. 22, 1957)

A trial manufacture was made to see the effect of the addition of miso yeasts by using 20,000 yests per $\mathrm{g}$. of miso in the mixing process of steamed soybeans and salted koji. The miso yeasts used in this trial, were of one of the most suitable strains for producing good flavor among the yeasts separated from ripened Shinshù type miso of high quality (cf. J. Soc. Brewing, Japan 50, 686(1956)).

The number of yeasts in miso was increased up to 300,000 per $\mathrm{g}$. of miso in 2 months, but decreased when the temperature of miso was higher than $35^{\circ} \mathrm{C}$. during the quick ripening. The examination of the control process showed that the number of yeasts which developed naturally in the miso without the addition of the starter was less than 10 per $\mathrm{g}$. of miso at the early stage, but it increased to $100,000-200,000$ in the same period of further ripening.

No significant difference could be detected between the results of chemical analyses of these two miso preparations. Only the flavor of the yeast-added miso was slightly superior to that of the other in the sensory test, but the difference was not so great as was expected.

This method may need further studies.

\section{Studies of pot still spirit}

Part 3. On the quality and the variance of composition in the distillates of a pot still spirit.

(No.12 983)

by

\author{
H. Kato, T. Nakano, J. Ushijima, T. Shimada, K. Shigaki (Kumamoto Tax \\ Admin. Bureau), S. KAyAshima (Kumamoto Brew. Laboratory Co.Ltd.) and K. HisA- \\ No (Yoshimura Brew. Co. Ltd.)
}

(Received nov. 7, 1957)

This paper cocerns the quality and the variance of composition in the partial distillates of the spirit, distilled industrially by pot still.

1. The larger amount of fusel oil, aldehyde and ester are in the distillate of high alcohol concentration as have been already indicated in the laboratory.

2. The variance of acid methyl alcohol in the different portion of distillate could not be presented so simply, as have been considered so far.

3. We suppose that it is better to collect only the middle running (alcohol 55-20\%) of the distillate, excepting foreshots and tailing, which are very poor in quality. Each of foreshots and tailing should be separately redistilled. 


\title{
Studies on the detection and the determination of gluconic acid in Saké
}

(No.12 988)

\author{
by \\ Masayuki Mikata, Hiroshi Imanaka \\ ( 2 chōme, Nihonbashi-honchō, Chūō-ku, Tokyo, Japan)
}

(Received Nov. 25 1957)

There are many investigations concerning the organic acids contained in Saké but only a few papers on the existence of gluconic acid. However, the identification and quantitative determination of this acid in Saké have not yet been performed.

The authors attempted to determine quantitatively the gluconic acid in Sake from the view point of the mechanism of gluconic acid fermentation.

After fractionation with ion exchange resin and paper chromatography, the quantitatively spotted gluconic acid was eluted from the developed section of filter paper and then back-titrated with $\mathrm{N} / 100 \mathrm{HCl}$.

Moreover, crystalline phenylhydrazide was obtained from the gluconic acid fraction and it was identified as phenylhydrazide of gluconic acid by melting point determination and micro-elementary analysis.

The result was as follows: phenylhydrazide of gluconic acid:m.p. $198.5 \mathrm{C}$, found $\mathrm{C}=50.47 \%$. $\mathrm{H}=6.48 \%, \mathrm{~N}=10.00 \%$ ). calcd. $\mathrm{C}=50.34 \%, \mathrm{H}=6.34 \%, \mathrm{~N}=9.79 \%$, (Gluconic acid contained in Saké amounted to about $0.025-0.045 \%$, corresponding to about $15-30 \%$ of total acid.

\section{Enzymatic basis of the coloring \\ Enzymological studies on the browning of kôji (Part IV)}

(No.12 1015)

by

Hideya Murakami and Mitori KawaI (Brewing Experimental Station, Tax Administration Agency)

(Received Nov. 15, 1957)

The influences of heating and addition of reagents on the browning of kôji extract were studied. The origin of the browning was assumed to be attributed to the activity of tyrosinase or o-polypenol oxidase in the kōji extract. 